\title{
CARS guidelines for Scholarly Video communication
}

\author{
Heinz U. Lemke ${ }^{1}$ - Dirk Wilhelm ${ }^{2}$
}

Accepted: 18 March 2021 / Published online: 8 April 2021

(c) CARS 2021

\section{From Scholarly Records to Scholarly Videos}

The purpose of the CARS guidelines for Scholarly Video Presentations is to provide a framework for translating the content of IJCARS publications, defined as Scholarly Records (SR), into Scholarly Videos (SV) [1].

Essential characteristics of a Scholarly Record, according to MV Dougherty [2], are defined as:

1. Putatively advance or summarize knowledge (Knowledge Condition).

2. Appear under identifiable authorship (Authorship Condition).

3. Be issued through an academic publisher (Publication Condition).

4. Be catalogued in university libraries (Library Condition).

5. Be catalogued in research data bases (Database Condition).

6. Belong to at least one recognized academic discipline (Discipline Condition).

No equivalent and generally accepted definition of Scholarly Videos exists as yet. However, if a Scholarly Video is expected to be presented at a CARS Congress and potentially also to be included into a CARS Academy database, a working definition of a Scholarly Video could be stated as:

Heinz U. Lemke

hulemke@cars-int.org

Dirk Wilhelm

dirk.wilhelm@tum.de

1 International Foundation for Computer Assisted Radiology and Surgery, Klettgaustrasse 20, 79790 Kuessaberg, Germany

2 Klinikum rechts der Isar, Technical University Munich, Klinik und Poliklinik für Chirurgie, Ismaningerstr. 22, 81675 Munich, Germany
1. Content conformity to IJCARS Scholarly Record (Knowledge Condition).

2. Appear under identifiable authorship(s) (Authorship Condition).

3. Realised through an academic/non-profit curation process (Publication Condition).

4. Be catalogued in university/non-profit databases (Database Condition).

5. Belong to at least one recognized academic discipline (Discipline Condition).

The overarching purpose of the video presentation process of Scholarly Records in the context of Computer Assisted Radiology and Surgery (CARS) as a scientific/ medical domain could be defined as:

To enable the effective exchange/communication of R\&D ideas by means of verbal, visual and written statements made by creative presenters, evaluated by informed curators, and utilized by an open-minded audience, with the aim to provide value and to stimulate complimentary thoughts and actions within the given domain of discourse by all parties involved in the scientific/medical communication process.

This definition implies a potentially different type of interactive navigation through knowledge in the domain of scholarly communication by all parties involved, i.e. authors, presenters, audiences and discussants [1]. If a video presentation is used as a tool in this process supported by appropriate enabling technologies, it should follow the communication categories:

To inform, to persuade and to entertain.

SRs of original articles, systematic reviews, short communications and extended abstracts submitted for video presentations to the CARS Congress and/or CARS Academy should, therefore, take account of the opportunities new media of communication can offer as regards to be Informative, Persuasive and Entertaining (IPE). Figure 1 shows 
Fig. 1 Characteristic criteria relating to SRs and SVs

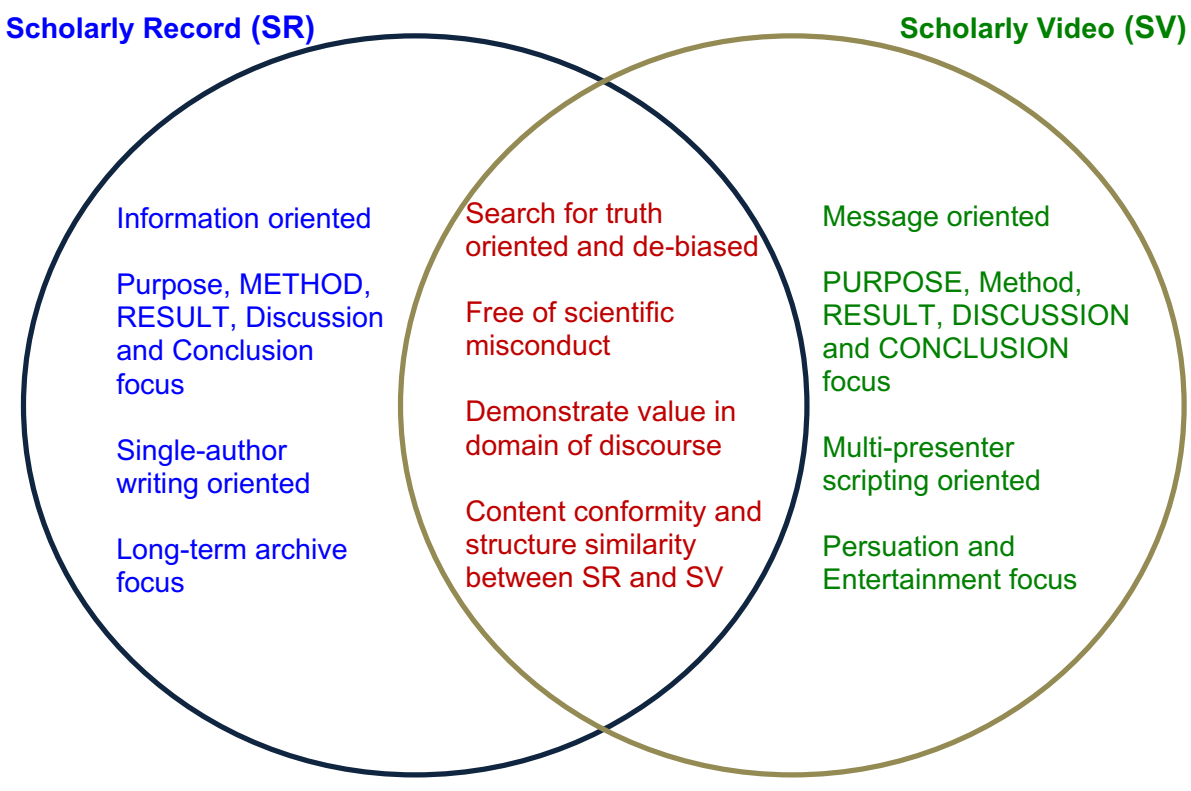

some commonality and difference in characteristic criteria relating to SRs and SVs.

Because video presentations serve interested parties often as the first encounter for an article/abstract presented at a CARS Congress and catalogued in an electronic database, they should rise interest for the content by as many members of this audience as possible, not least to also download the article/abstract or contact the authors directly for further enquiry (Q\&A). Assuming that the audience expects some in-person communication features [3] also being present in a video, this represents an additional challenge in the scripting of a video presentation. Typical members from the CARS audience may come from institutions of higher education, medical practitioners, healthcare decision makers, industry and research, as well as interested members of the general scientific/medical community.

\section{Examples of criteria and visuals/graphics for Scholarly Videos}

Following the IPE communication categories as guiding principles for navigating through scholarly knowledge, they should be embedded in a well thought out and clear script/ storyline, suitably structured along the traditional publication sections of Purpose, Methods, Results and Conclusion.

In particular, presenters may keep in mind the following criteria when preparing a script:
- Content conformity and structure similarity with SR.

- Demonstrate value in domain of discourse.

- Message communication oriented.

- Purpose, Result and Discussion focus.

- Multi-author/presenter and dialogue oriented.

- Persuasion oriented.

- Curiosity-rising entertainment.

Other criteria known from the IJCARS SR review process such as "Search for truth oriented and de-biased" as well as "Free of scientific misconduct", apply in the usual manner.

In Table 1, some selected examples of visual/graphic presentations for the Purpose, Methods, Results and Conclusion sections of the IJCARS SRs may serve as an entry point for designing SVs and for being considered in the SV curation process.

\section{Curation process of video presentations}

Similar to the IJCARS Scholarly Editorial Review Process, a video of a definitive publication /SR is subject to a rigorous TRAP (Triaging, Reporting and Arbitration Process) and if successful, to a follow-up IPE (Informative, Persuasive and Entertaining) curation process, see Fig. 2. It is assumed, however, that the Method and Result sections of the SV have been thoroughly reviewed and completed as part of the SR PREP (Publication, Reviewing and Editing Process). 
Table 1 Selected examples of visual/graphic presentations for the purpose, methods, results and conclusion sections of IJCARS SRs for corresponding parts of a Scholarly Video Presentation

\begin{tabular}{|c|c|c|c|c|}
\hline Section & Purpose & $\begin{array}{l}\text { Materials and } \\
\text { Method }\end{array}$ & Results & $\begin{array}{l}\text { Discussion and } \\
\text { Conclusion }\end{array}$ \\
\hline Informative & $\begin{array}{l}\text { need analysis, } \\
\text { position in (clinical) } \\
\text { workflow, impact } \\
\text { on health } \\
\text { care/economy }\end{array}$ & $\begin{array}{l}\text { highlighting of } \\
\text { uniqueness, } \\
\text { visual models, } \\
\text { point of view } \\
\text { models }\end{array}$ & $\begin{array}{l}\text { visualize } \\
\text { "now" and } \\
\text { before, added } \\
\text { value }\end{array}$ & $\begin{array}{l}\text { bias and assumptions, } \\
\text { convergent and divergent } \\
\text { viewpoints relating results } \\
\text { to the state of the art, top- } \\
\text { down and bottom-up } \\
\text { views, visuals without bias }\end{array}$ \\
\hline Persuasive & $\begin{array}{l}\text { problem visuals } \\
\text { including use of } \\
\text { mental imagery, } \\
\text { journal headlines, } \\
\text { "need" graphics }\end{array}$ & $\begin{array}{l}\text { originality but } \\
\text { simplicity of } \\
\text { method, visual } \\
\text { cues }\end{array}$ & $\begin{array}{l}\text { highlighting of } \\
\text { uniqueness, } \\
\text { visual models, } \\
\text { point of view } \\
\text { models }\end{array}$ & $\begin{array}{l}\text { visualize "now" and } \\
\text { projection into the future, } \\
\text { multivariate viewpoints, } \\
\text { call for action, inspiring } \\
\text { visuals including use of } \\
\text { visual saliency, multiple } \\
\text { viewpoint visualization, } \\
\text { self-critical and } \\
\text { scrutinizing }\end{array}$ \\
\hline Entertaining & $\begin{array}{l}\text { interview with } \\
\text { potential users, } \\
\text { scribing of bullet } \\
\text { points, analogues, } \\
\text { episodes, stories, } \\
\text { strategic coloring }\end{array}$ & $\begin{array}{l}\text { back to the } \\
\text { roots, history of } \\
\text { related } \\
\text { methods, } \\
\text { construction of } \\
\text { set-up }\end{array}$ & $\begin{array}{l}\text { contrasting } \\
\text { results, } \\
\text { controversial } \\
\text { results }\end{array}$ & $\begin{array}{l}\text { multi-dimensional } \\
\text { visualization, gamification, } \\
\text { targeted "graphic } \\
\text { recording/reporting", } \\
\text { visual story-telling, patient } \\
\text { impact/delivery }\end{array}$ \\
\hline
\end{tabular}

In order to avoid a repetition of this activity in the curation process, only the fidelity (content conformity and structure similarity) between the SR and SV is being checked.

In the curation activity, an SV will be given points (0-10) relating to each element as indicated in Table 1 for fulfilling the requirements to inform, to persuade and to entertain. The sum total of points given to all 12 elements serves to categorize the video presentation into:

100-120 Very good (qualifies for in-person session presentation and for the SV award session)

80-99 Good (selected SVs may qualify for in-person session presentation and for an SV award)

60-79 Satisfactory

0-59 Unsatisfactory
As can be observed from the above categorization, of particular concern is the inclusion of SVs into the CARS Academy and for exposed presentation at the CARS Congress. Presenters of SV are therefore given the opportunity to revise/edit their SV if desired and if time permits.

\section{Technical check and registration of video presentations}

Both the Technical Check and Registration of Video Presentations as shown in Fig. 2 are considered to be predefined processes with high transparency and reproducibility. They are subject to the state of the art provided by modern media technologies and need to be updated in regular intervals. 


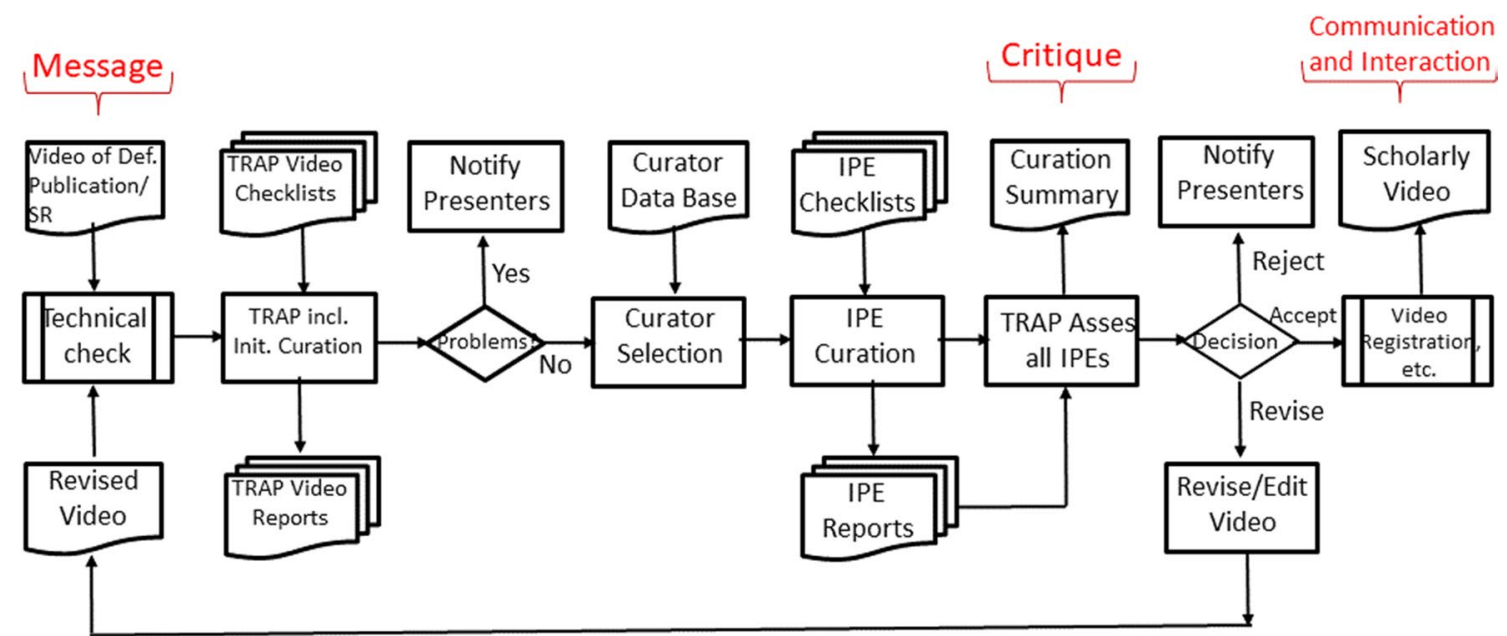

TRAP - Triaging, Reporting and Arbitration Process IPE - Informative, Persuasive and Entertaining SR - Scholarly Record

Fig. 2 CARS Scholarly Video curation process

\section{References}

1. Lemke HU, Feussner H, Berliner L (2020) Editorial on guiding principles for video presentations of IJCARS articles and long abstracts. Int J CARS 15:897-899. https://doi.org/10.1007/ s11548-020-02213-z

2. Dougherty MV (2018) Correcting the scholarly record for research integrity: in the aftermath of plagiarism. Springer, Berlin
3. Feussner H, Lemke HU (2020) Preface on analogue and digital CARS 2020 congress. In: IJCARS proceedings suppl., June 2020, CARS 2020 - computer assisted radiology and surgery, Munich, Germany. Int J CARS, vol 15, pp. 1-214. https://doi.org/https:// doi.org/10.1007/s11548-020-02171-6H

Publisher's Note Springer Nature remains neutral with regard to jurisdictional claims in published maps and institutional affiliations. 